\title{
New Public Management 2.0
}

\section{Liebe Leserinnen und Leser,}

öffentliche Verwaltungen haben keinen besonders guten Ruf.

Wer sie als ein Beispiel für Unwirtschaftlichkeit oder Trägheit darstellt, wird kaum Widerspruch ernten, bedient er doch ein übliches Klischee. Daran ändert auch nichts, dass Zuwanderer die deutsche Verwaltung wegen ihrer Funktionsfähigkeit und Präzision zumeist loben - die Erfahrungen in vielen anderen Ländern sind deutlich schlechter. Was stimmt nun? Wie so häufig beides.

Wir können durchaus auf unsere Verwaltung stolz sein. Dennoch muss sie einen großen Sprung nach vorne machen, um angesichts der einschneidenden Veränderungen - denken Sie nur an die demografische Entwicklung - und der daraus resultierenden drängenden Probleme auch in Zukunft handlungsfähig zu bleiben. Die Verwaltung muss lernen, schneller auf Wandel zu reagieren, sie muss noch konsequenter den $\mathrm{Zu}-$ sammenhang zwischen zu erfüllenden öffentlichen Aufgaben und den dafür erforderlichen Prozessen und Ressourcen im Griff haben. Hierfür ist die traditionelle inputorientierte Steuerung auf Basis von bürokratischen Vorgaben beispielsweise durch Gesetze und Verordnungen nicht mehr hinreichend geeignet. Es mangelt ihr an Integration des für gute Regeln notwendigen Wissens und an Change-Management-Knowhow. Die Verwaltung muss ihre Steuerung verändern, sie muss deutlich mehr wie private Unternehmen geführt werden. Der international hierfür übliche Begriff ist der des New Public Managements. Einem Controller ist das damit verbundene Vorgehen sehr geläufig. Es geht unter anderem um die Formulierung von Zielen, um systematische Rückkopplungen des erreichten Ist gegen diese Ziele und schließlich auch um die Motivation der Mitarbeiter für die Zielerreichung. Controller spielen deshalb bei der Implementierung der Steuerung auch eine wichtige Rolle.

Trotzdem haben Controller es nicht verhindern können, dass viele bisherige Versuche, zielorientiert zu steuern, nicht erfolgreich waren. Die Liste der Fehlschläge ist lang, und das nicht nur in Deutschland. Oft waren die Erwartungen gänzlich blauäugig. Grundlegende Veränderungen der Steuerungslogik passieren weder schnell noch ganz von alleine. Ein

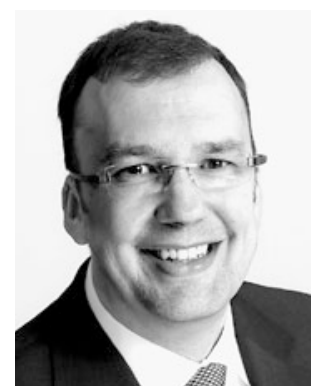

Utz Schäffer

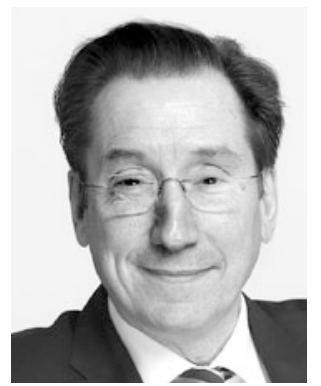

Jürgen Weber derartiger Wandel greift tief in die Organisationskultur ein und schafft Ängste bei den Mitarbeitern, was wiederum zu Widerstand und Reaktanz führt. Diese "menschliche Seite“ ist bisher vernachlässigt worden. Man glaubte, dass die reine Einführung neuer Instrumente - insbesondere der Kostenund Leistungsrechnung oder der Balanced Scorecard - ausreichen würde. Weit gefehlt: Mehr als Instrumentenruinen sind häufig nicht dabei herausgekommen.

Heute können wir viele Verwaltungen sehen, die einen neuen Anlauf machen, dem Konzept der Zielorientierten Steuerung zum Durchbruch zu verhelfen. Einige davon sind in diesem Sonderheft vereint. Deren gesammeltes Wissen macht große Hoffnung, dass der Weg aus einer schwerfälligen Bürokratie doch gelingen kann.

Viel Spaß bei der Lektüre wünschen Ihnen
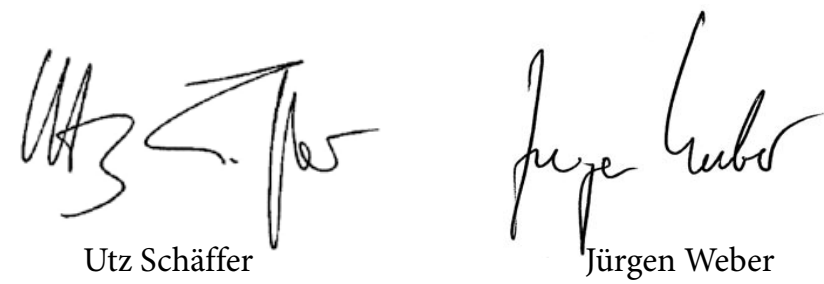